\title{
Cataloguing Electronic Resources
}

by the Cataloguing Team at Charles Sturt

University

The workbook used at the conference is attached as a supplementary file.

Welcome:

- Objective: To provide an understanding of cataloguing electronic resources that you can use in your local environment

- Cover a broad overview rather than the minutiae of details associated with cataloguing 
CHARLES STURT

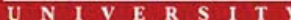

Your programme for this session:

$>$ First Steps

$>$ Cataloguing eBooks

$>$ Cataloguing integrating resources

$>$ Cataloguing ejournals

$>$ What's Coming soon?

\section{CHARLES STURT}

\begin{tabular}{llllllllll}
\hline & N I V E R S I T Y
\end{tabular}

\section{Scope: Electronic resources}

Chapter 9 AACR2

The term electronic resources applies to all resources that are encoded

for manipulation

by a computerised device 
CHARLES STURT

4 U N I V E R S I T Y

Electronic resources consist of:

-Text

-Programs

-Combination of data and program

Which type of record do you use in the Leader/06?

Do you have an Electronic resource of

'a' Text, language material

'm' Computer Files or programs

\section{Five foundation concepts for e-resources}

1. Direct vs remote access

2. Granularity

3. Content vs carrier

4. Multiple characteristics

5. Type of publication 


\section{Direct vs Remote}

Direct:

Physical carrier can be handled

Can be inserted into a computerised device

Examples: CD Roms, DVDs

Remote:

No physical carrier

You use an input-output device (terminal)

Connected to a computer system (network)

Or to resources on a storage device (hard disk)

\section{CHARLES STURT}

\begin{tabular}{lllllllll} 
U N I V E R S I T Y & \\
\hline
\end{tabular}

\section{Granularity}

Is the resource part of a larger resource?

Eg Web sites with subscriptions levels nested within

higher levels, up to the domain

Which level are you cataloguing?

Online image collection or individual image

One record for the web site

Separate records for sub-level pages of the site 


\section{Content vs carrier}

\section{Content}

Primary intellectual or artistic content

> Language > Sound > Computer Program

Most records have 'a' for language material

\section{Carrier}

> Printed paper > online html page > online pdf file

\section{Multiple versions}

The same content can be carried on multiple version

Examples

> Printed paper > online html page > online pdf file

> Print

$>$ microfilm

$>\mathrm{cd}$ rom 


\section{CHARLES STURT}

\section{U N I V E R S I T Y}

\section{Multiple versions - CHALLENGES}

$>$ Create multiple records?

$>$ Create single record?

$>$ How to link records for different formats

$>$ How to make relationships clear?

What does the National Library require?

Libraries Australia recommends the creation of separate records when a resource exists in both electronic and non-electronic form

\section{Type of record:}

a: $\quad$ Online text

e: $\quad$ Online map

j: $\quad$ Online musical sound recording

m: online programs or interactive games 
How is a resource published in time?
4. Finite:
issued in a finite number of parts
Continuing:
issued over time with no conclusion

5. The 3 types

$>$ Monographs

$>$ Serial

$>$ Integrating

\section{CHARLES STURT}

\section{U N I V E R I T Y}

Type of Issuance

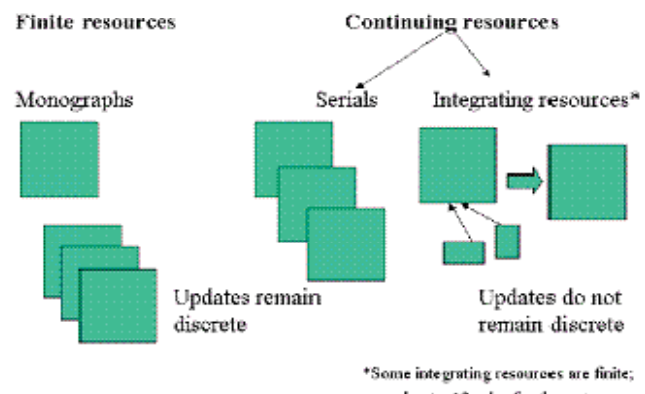

use chunter 12 rules for them too. 
Revision: Before editing a record -

1. Granularity:

2. Primary content:

Carrier:

3.Type of record

4. Published as:

5. Published as eg Russian dolls

text, sound, image, map

CD Rom, online pdf file, online mp3 file

Language, Computer file

finite or continuing

Monograph, serial or integrating resource

\section{CHARLES STURT}

\section{U N I V E R S I T Y}

Don't try to catalogue the whole WWW

1. Authority Who is responsible / publisher / webmaster?

2. Accuracy: Look for facts that are verifiable, check the domain name for the type of publisher

3. Purpose of content: How valuable, biased, discriminatory, objective,

4. Age/timeliness: How old is the information in relation to new technologies,

5. Audience level: general or specific

6. Access: Appearance of content, links go directly to database or more links,

Do you still want to catalogue the site? 
Add your selection criteria for electronic resources to your library's Collection Development Policy

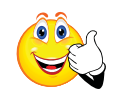

\section{Cataloguing online books}

3 different types of "eBooks"

- Online pdf

- Online html

- Online as a reproduction 
CHARLES STURT

U N I V E R S I T Y

\section{Record for eBook}

\begin{tabular}{|c|c|}
\hline$\underline{\text { Leader/06 }}$ & Type of record \\
\hline a & language material \\
\hline $\mathrm{m}$ & computer file (restricted) \\
\hline$\underline{\text { Leader } / 07}$ & Bibliographic level \\
\hline $\bar{a}$ & Monographic component part \\
\hline i & Integrating resource \\
\hline $\mathrm{m}$ & Monograph/item \\
\hline $\mathrm{s}$ & Serial \\
\hline
\end{tabular}

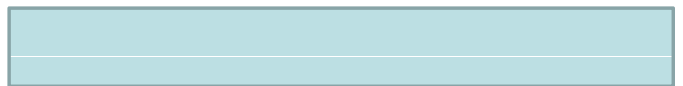

\section{CHARLES STURT}

U N I V E R S I T Y

DIVISION OF LIBRARY SERVICES

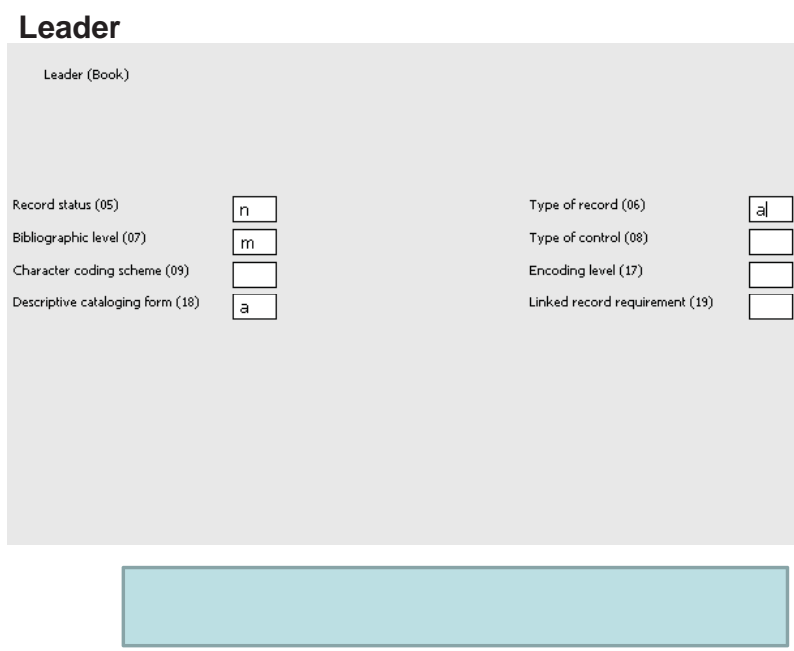


CHARLES STURT

U N I V E R S I T Y

DIVISION OF LIBRARY SERVICES

\section{Field 006}

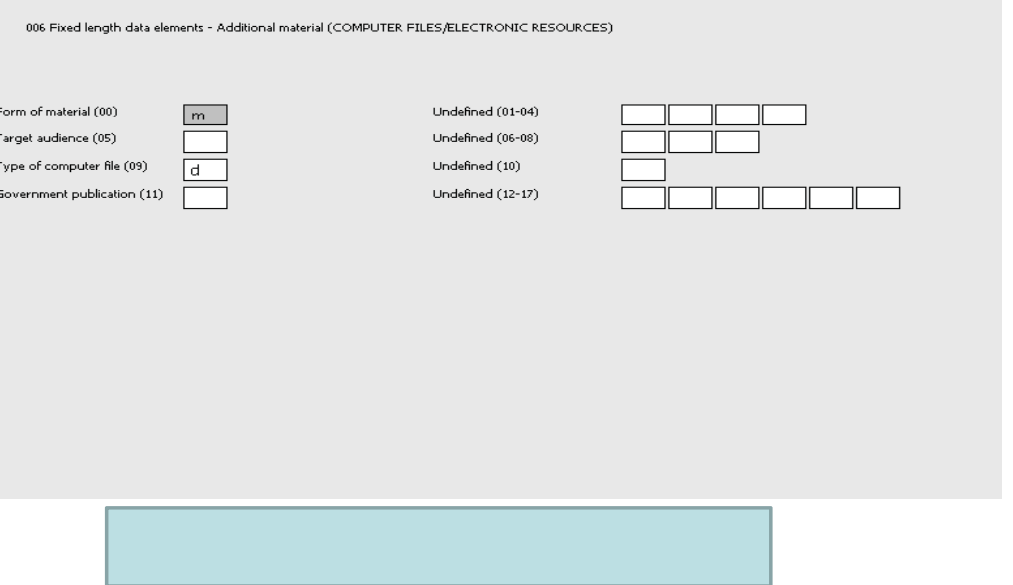

DHARLES STURT

\begin{tabular}{llllllllll}
\hline & $N$ & I & V & E & R & $S$ & I & $T$ & $Y$
\end{tabular}

\section{Field 007}

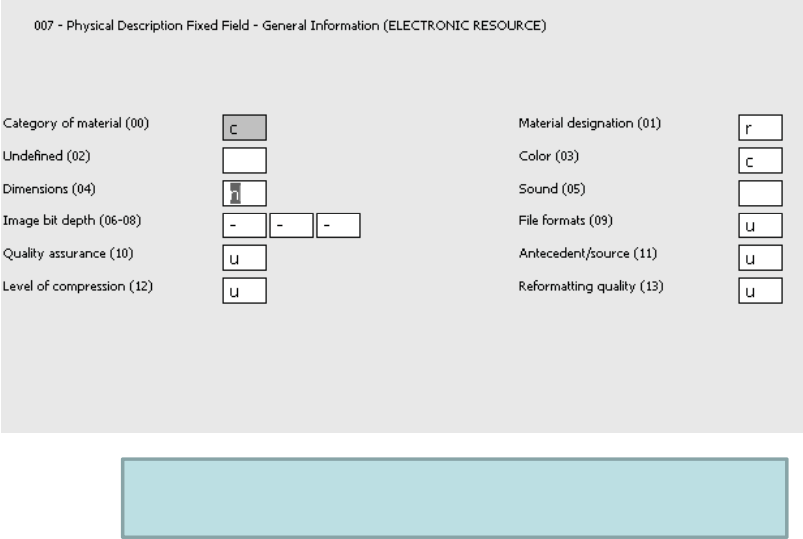




\section{Field 008}

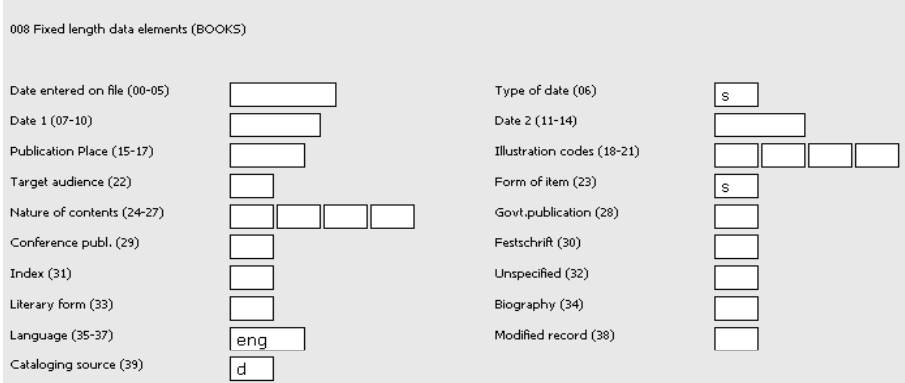

CHARLES STURT

U N I VER S I T Y

\section{Source of the title for online books?}

Look for evidence that provides the complete information

title screen,

homepage,

metadata,

Html header

Pdf title page

\$a Eureka \$h [electronic resource] 


\section{Notes}

All electronic resources require a note to identify the source of the title

500a Title from pdf title page ( viewed 9 July 2009)

500 a Title from table of contents page (viewed 3 July 2008)

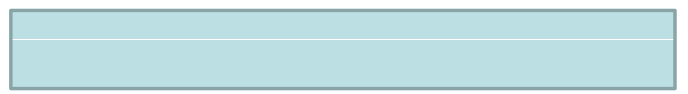

CHARLES STURT

$\begin{array}{llllllllll} & \text { U N I V } & \text { E } & R & S & \text { I } & T & \text { Y }\end{array}$

\section{Physical description for eBooks}

300 a 1 electronic text b html file

For an exact reproduction

use the pagination etc of the original print

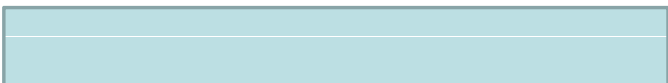




\section{Essential notes in online monographs}

500 source of title (date viewed)

538 Mode of access:

Optional notes

538 Systems requirements:

530 Other formats

520 Summary

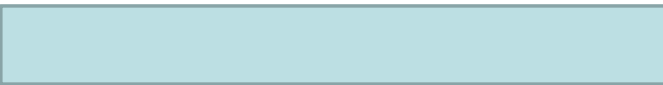

\section{Electronic location and access}

85641 \$u http://www

\$z Public note eg Click here

Electronic version

Not available for document delivery

In opac the URL is a hyperlink to the internet location 


\section{CHARLES STURT \\ $\frac{U \text { U I V E R S I T Y }}{\text { U }}$}

\section{Exact Reproduction}

When cataloguing an e-book as a reproduction use

533 Details of reproduction

533 a Electronic reproduction b Paris c OECD d 2009

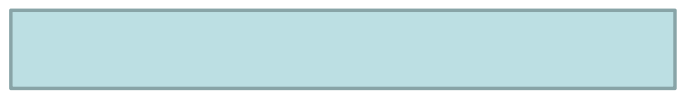

MHARLES STURT

5) U N I V E R S I T Y

\section{Reminder: Integrating resources}

\section{Type of Issuance}

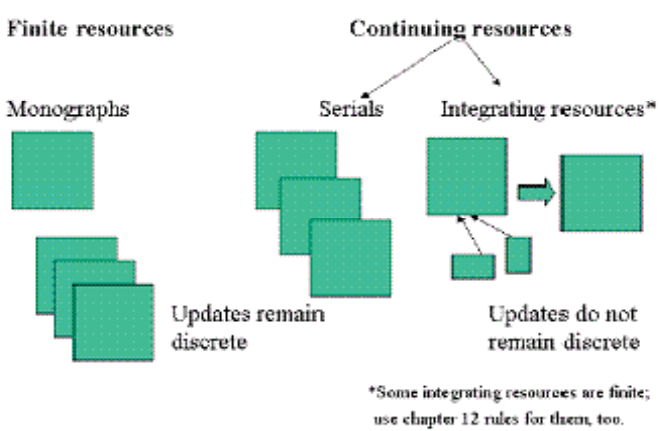




\section{What is an integrating resource?}

A bibliographic resource that is changed by updates, and integrated into the whole resource.

Print - Loose-leaf; Online - web sites;

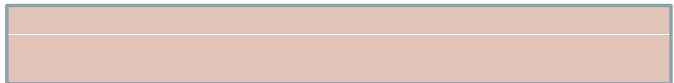

\section{Leader 06}

Primary content of the resource

a language

$\mathrm{m}$ computer file restricted use

OR e, j,

\section{Leader 07}

$$
\begin{array}{ll}
\text { m } & \text { monograph } \\
\mathrm{s} & \text { serial } \\
\mathrm{i} & \text { integrating }
\end{array}
$$


CHARLES STURT

U N I V E R S I T Y

\section{Leader}
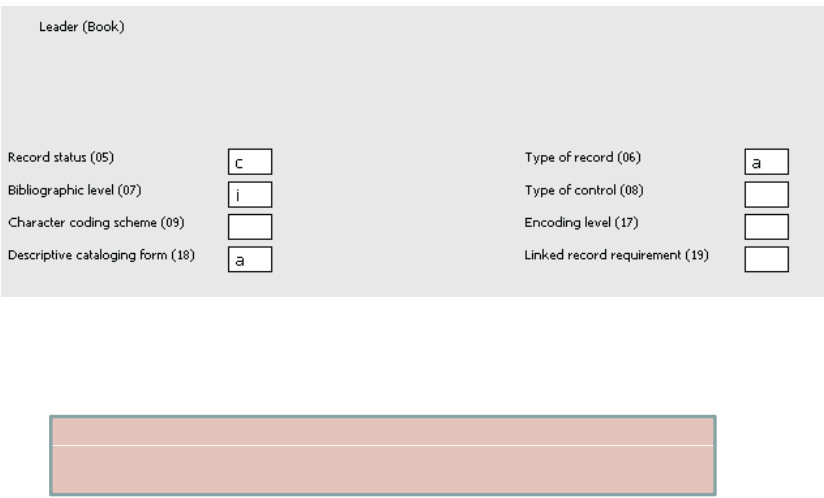

CHARLES STURT

54 U I I E R S I T Y

Field 006

Integrating resources is similar to serials

Frequency Updating continuously, Not Known

Regularity

04/ type of continuing resource, d or w

Updating database, Updating website

Form of item s (electronic) 
CHARLES STURT

U) U I V E R S I T Y

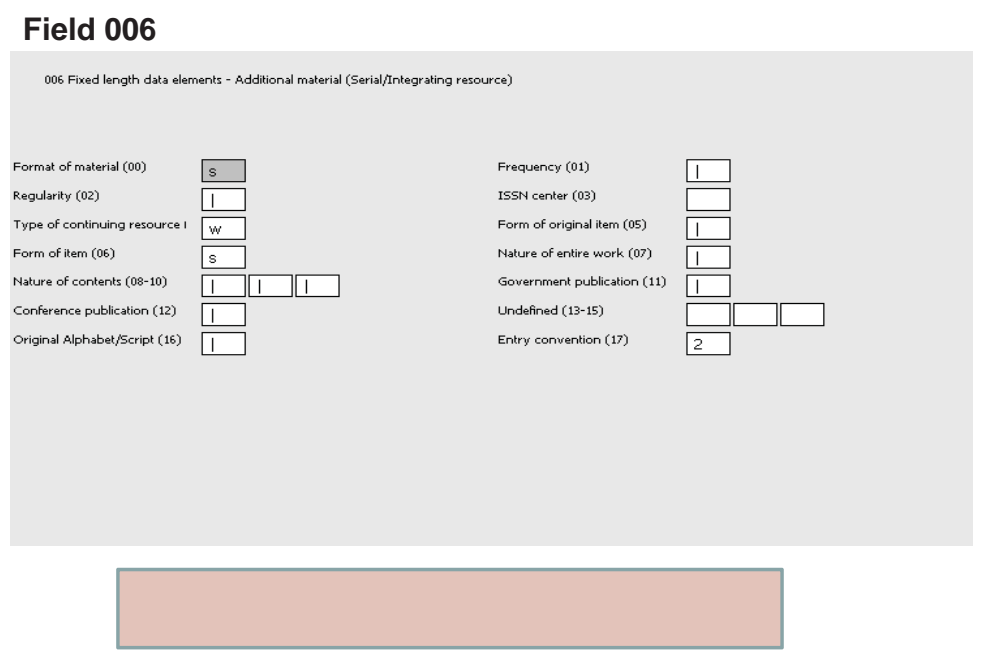

CHARLES STURT

\begin{tabular}{llllllllll}
\hline$U$ & $N$ & I & V & E & $R$ & $S$ & I & $T$ & $Y$
\end{tabular}

DIVISION OF LIBRARY SERVICES

Field 007

007 - Physical Description Fixed Field - General Information (ELECTRONIC RESOURCE)

$\begin{array}{llll}\text { Category of material (00) } & \text { Material designation (01) } \\ \text { Undefined (02) } & \text { Color (03) } \\ \text { Dimensions (04) } & \text { Sound (05) } \\ \text { Image bit depth (06-08) } & \text { File formats (09) } \\ \text { Quality assurance (10) } & \text { Antecedent/source (11) } \\ \text { Learel of comprescion (12) } & \text { Reformatting quality (13) }\end{array}$

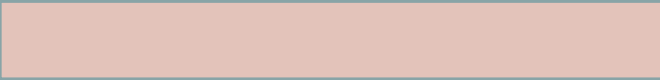




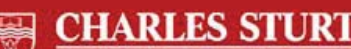

45 N I V E R S I T Y

DIVISION OF LIBRARY SERVICES

Field 008

008 Fixed length data elements (BOOKS)

Date entered on file (00-05)

Date 1(07-10)

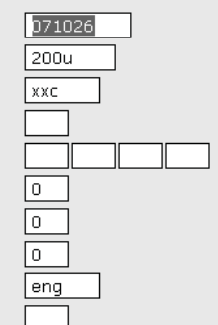

Type of date (06)

Date 2(11-14)

Publication Place (15-17)

Target audience (22)

Nature of contents (24-27)

Conference publ. (29)

Index (31)

Literary form (33)

Language (35-37)

Cataloging source (39)

Illustration codes (18-21)

Form of item (23)

Govt.publication (28)

Festschritt (30)

Unspecified (32)

Biography (34)

Modified record (38)

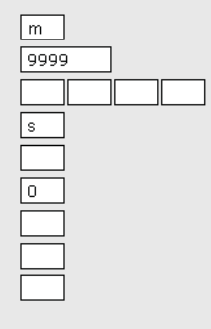

Where is the title?

Displayed on the homepage

In the HTML header title

Title screen, menus, metadata

More in Chapter 9 \& 12

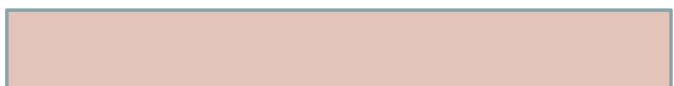




\section{CHARLES STURT}

What about publisher and place?

\section{Publisher}

is responsible for making the resource available on the Internet

Is preferably a corporate body (not the author)

\section{Place}

You might have to search a few pages

Click on a corporate name to get a location,

Check if you have moved to a different domain name

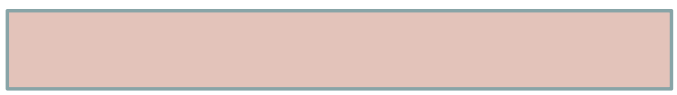

\section{CHARLES STURT}

\section{\begin{tabular}{lllllllllll}
\hline & N & I & V & E & R & $S$ & I & $T$ & $Y$
\end{tabular}}

Date - is that the easy part?

Integrating resources have a range of dates

Ongoing/continuing : open date 2009-

Closing date: 2003-2009 


\section{Note areas}

Essential

500 Source of title proper (date viewed)

538Mode of access:

If applicable

538 System requirements

530 Other formats

310 Frequency of updates

Value adding

520 Summary

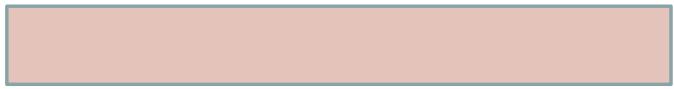

\section{CHARLES STURT}

$\begin{array}{llllllllll}\text { U N I V E R S I T Y } & \text { I }\end{array}$

\section{Linking /Relationships-}

When to use 776

You also have a physical format, add the ISBN/ISSN

You have a separate existing online version already catalogued separately

77608 \$i Also available in CD Rom version

\$t Environmental warriors

\$x1531-1540

\$w 00123687 


\section{Electronic location and access}

85641 \$u http://

\$z Public note - Requires free registration

The integrating resource has changed - do I change the record??

Integrating entry for "minor" changes - are they defined?

A new record may be created because of changes, if the resource in the existing record still exists.

See $12.2 \mathrm{~F}$ 


\section{CHARLES STURT}

\section{UN I VER S I T Y}

DIVISION OF LIBRARY SERVICES

\section{Challenges}

Searching for records! How many fields do I have to check?

The record looks different from the rules in this workshop

I have a later iteration - I change description, location, notes, 008 , but accept the $260 \$ c$

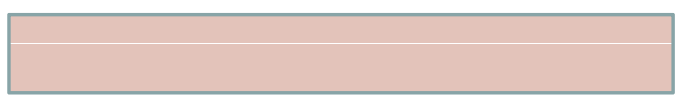

\section{Electronic journals}

How are online journals different from print?

Discrete parts can be print issues, but online can also be articles

- Born digital

- Online versions of print

- Part of a database 


\section{CHARLES STURT}

U N I V E R S I T Y

\section{Leader 106}

Primary content ' $a$ ' language material vs carrier

\section{Leader 107}

s serial

\section{CHARLES STURT}

U N I V E R S I T Y

\section{Field 006}

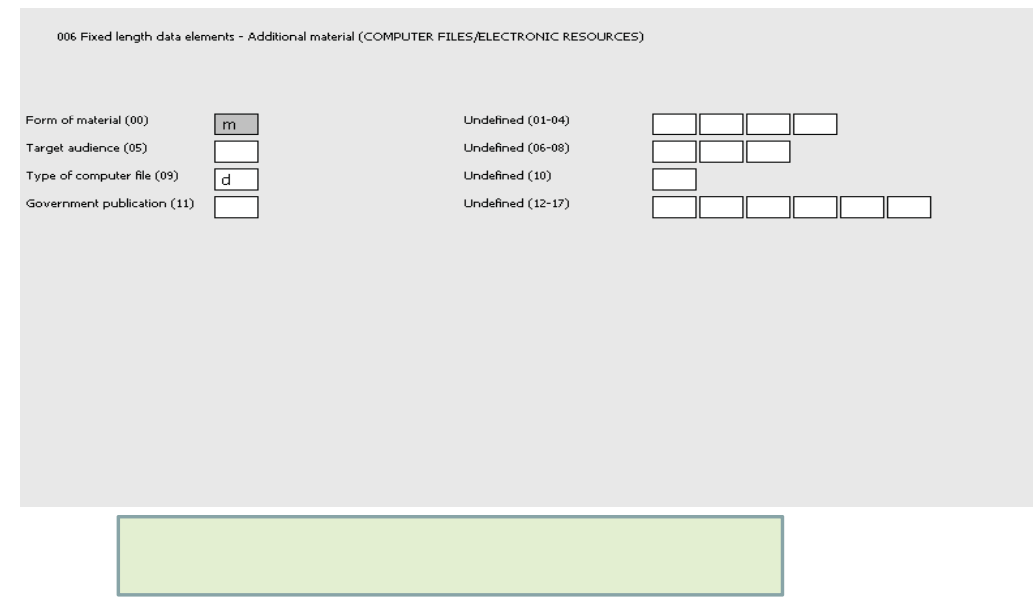




\section{CHARLES STURT \\ \begin{tabular}{lllllllllll}
\hline & U A I & V & $E$ & $R$ & $S$ & I & $T$ & $Y$
\end{tabular}}

\section{Field 007}
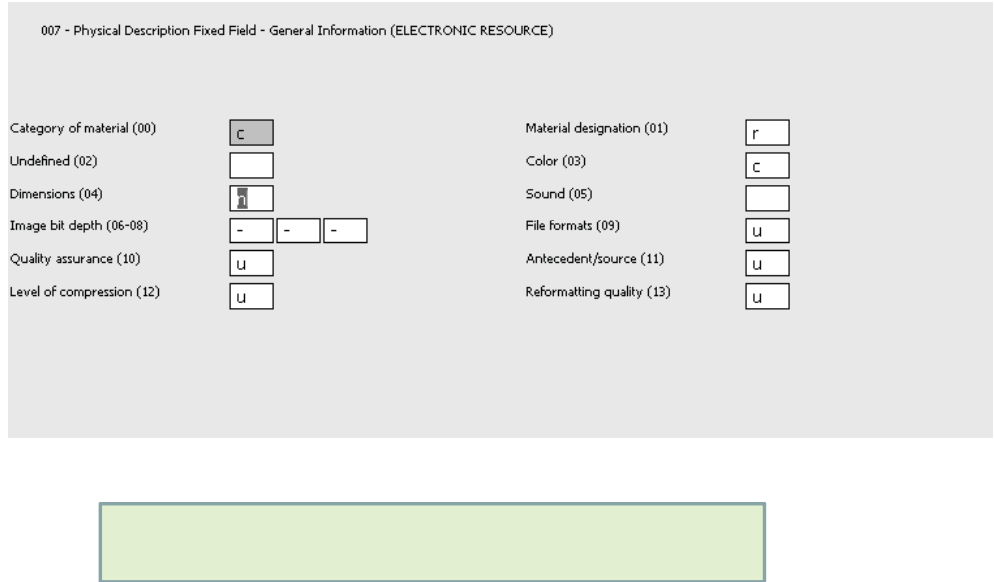

\section{CHARLES STURT}

U N I V E R S I T Y

\section{Field 008}

Date entered on file (00-05)
Date 1 (07-10)
Place of publication code (15-17)
Regularity (19)
Type of continuing resource (21)
Form of item (23)
Nature of contents (25-27)
Conference publ. (29)
Alphabet/5cript (33)
Language (35-37)
Cataloging source (39)

Type of date (06)

Date 2 (11-14)

Frequency (18)

ISSN center (20)

Form of original item (22)

Nature of entire work (24)

Govt. publication (28)

Undefined (30-32)

Entry convention (34)

Modified record (38)

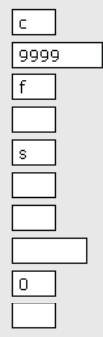


CHARLES STURT

45 U N I V E R S I T Y

\section{Notes, Notes, Notes}

500 Title from table of contents ( viewed 8 July 2009)

506 Available only to subscribing libraries

516 to describe the file or document formats

530 can be used to note the existence of other formats

538 Mode of access: All issues available via World Wide Web

538 System requirements: Requires Adobe Acrobat Reader

•7XX linking entries for related resources

-Electronic location

85640 \$u \$z 
CHARLES STURT

UN I V E R S I T Y

Homework for you - wow!

$>$ Read AACR2 Chapter 9

$>$ Check your institution's requirements for single or multiple records

$>$ Write criteria for online resources into your Collection Development Policy 